\title{
La fecundación asistida. ¿Historia de un debate interminable? El Informe de la Comisión Interamericana de Derechos Humanos*
}

\section{Assisted Fertilization. Story of an Endless Debate? The Report of the Inter-American Commission on Human Rights}

\author{
Ingrid Brena**
}

Sumario: I. La fecundación asistida, una opción a la infertilidad. II. Antecedentes del Informe. III. Derechos analizados en el Informe. IV. Test de la Comisión. V. Derecho a la igualdad ante la leye igual protección de la ley, artículo 24 de la Convención Americana sobre Derechos Humanos. VI. Recomendaciones de la Comisión Interamericana de Derechos Humanos. VII. Significado de la resolución en el continente americano. VIII. Bibliografía.

* Artículo recibido el 13 de septiembre de 2011 y aprobado para publicación el 14 de octubre de 2011

Informe núm. 85/10 caso 12.36114 de julio de 2010 .

** Investigadora en el Instituto de Investigaciones Jurídicas de la UNAM. 
RESUMEN: La implementación de las modernas tecnologías reproductivas está generando importantes controversias sociales, políticas y jurídicas, muestra de ello, son los acontecimientos que han ocurrido y están ocurriendo en Costa Rica. Esto nos lleva a considerar que la situación se convierte en emblemática de lo que ocurre en el resto de esta región del Continente. Por ello, en este estudio me referiré al caso presentado ante la Comisión Interamericana de Derechos Humanos en contra del Estado de Costa Rica por haber prohibido a las presuntas víctimas tener acceso al tratamiento de fecundación in vitro en el país, en contravención de diversos derechos reconocidos en la Convención Americana de Derechos Humanos y que dio lugar al Informe 85/10EI que ahora se analiza.

Palabras clave: fecundación asistida, Comisión Interamericana de Derechos Humanos

ABSTRACT: The implementation of modern reproductive technologies is generating significant social controversies, political and legal proof of this are the events that have occurred and are occurring in Costa Rica. This leads us to believe that the situation becomes emblematic of what happens in the rest of the region. Therefore, in this study we will refer to the case before the Inter-american Commission of Human Rights against the State of Costa Rica because of the denial to IVF treatment to the alleged victims, in violation of various rights recognized in the American Convention on Human Rights that led to the report 85/10EI, now under consideration.

Descriptors: assisted fertilization, Inter-American Commission on Human Rights.

RÉSUMÉ: L'implémentation des techniques de reproduction modernes sont en train de générer d'importantes controverses sociales, politiques et juridiques, un exemple de cette situation sont les événements qui ont eu et sont en train d'avoir lieu au Costa Rica. Cela nous amène à croire que la situation devient emblématique de ce qui se passe dans le reste de cette région du continent. Par conséquent, dans cette étude on fera référence à l'affaire devant la Commission Interaméricaine des Droits de l'Homme contre l'Etat du Costa Rica à conséquence de la interdiction aux victimes présumées d'avoir accès aux traitements par FIV dans le pays, en violation des différents droits reconnus dans la Convention Américaine relative aux Droits de l'Homme qui a conduit au rapport 85 / 10EI qui on analyse.

Mots-clés: fécondation assistée, Convention Américaine relative aux Droits de l'Homme. 
Los índices de infertilidad se han incrementado en todo el mundo en forma alarmante durante los últimos años. Esta situación ha propiciado que un número cada vez mayor de parejas con problemas decidan acudir a las técnicas de reproducción asistida. América Latina no es ajena a esta situación, y en la mayoría de sus países se aplican actualmente diversas técnicas de reproducción asistida, entre las cuales se encuentra la fecundación in vitro.

La implementación de modernas tecnologías reproductivas está generando importantes controversias sociales, políticas y jurídicas; muestra de ello son los acontecimientos que han ocurrido en Costa Rica. Esto nos lleva a considerar que la situación se ha convertido en un emblema de lo que ocurre en el resto de la región. Por ello, en este estudio me refiero al caso presentado ante la Comisión Interamericana de Derechos Humanos (CIDH) en contra del Estado de Costa Rica. En primer término, presento una síntesis y sistematización del Informe y después trato de expresar cuál es, en mi opinión, el significado del Informe, tomando en cuenta que América Latina se encuentra en este momento sumida en un debate, el cual parece no tener fin.

En enero de 2001, dicha Comisión recibió una petición contra la República de Costa Rica en la que se alegaba la responsabilidad internacional del Estado por haber prohibido a presuntas víctimas tener acceso al tratamiento de fecundación in vitro en aquel país, en contravención a los diversos derechos reconocidos en la Convención Americana sobre Derechos Humanos.

Después de más de diez años, la Comisión Interamericana de Derechos Humanos presentó su Informe 85/10 el 14 de julio de 2010. Tanto el informe como las recomendaciones que de él se derivan forman parte de la primera etapa del procedimiento internacional instaurado por la Convención Interamericana sobre Derechos Humanos para la protección de esos derechos en el continente.

Si bien este documento no es una sentencia dictada por el órgano jurisdiccional, no carece por ello de fuerza jurídica. La propia Corte Interamericana de Derechos Humanos ha sostenido el alto valor que tienen 
los informes y las recomendaciones de la Comisión, así como la necesidad de que el Estado las tome en cuenta - considerando que la Convención Americana es el marco jurídico de dichos informes-, lo cual implica un sistema de compromisos que el Estado se ha ofrecido atender. La participación en un tratado internacional trae consigo el cumplimiento de todas las consecuencias que derivan de esa participación conforme a la buena fe. Una de esas consecuencias es la atención a las determinaciones adoptadas por los organismos previstos en el Tratado, como es el caso de la Comisión, la cual actuó en términos de su encomienda.

Notificadas las recomendaciones a la República de Costa Rica, la Comisión Interamericana concedió varios plazos a este Estado para el cumplimiento de las mismas. El último se venció el pasado 31 de julio de 2011, sin que Costa Rica las haya acatado mediante la emisión de una legislación sobre fertilización asistida que cubra los requerimientos exigidos en la resolución. En consecuencia, el pasado mes de agosto, la Comisión Interamericana turnó el caso a la Corte Interamericana de Derechos Humanos para que ésta, como órgano jurisdiccional, decida el asunto en forma definitiva a través de una sentencia.

\section{ANTECEDENTES DEL INFORME}

Por el Decreto Ejecutivo núm. 24029-S del 3 de febrero de 1995 se reguló en Costa Rica la fecundación in vitro, conocida por las siglas FIV. La regulación era ya restrictiva de origen, pues se aplicaba sólo a parejas conyugales, prohibía la fertilización de más de seis óvulos por ciclo de tratamiento y exigía que todos los óvulos fertilizados en un ciclo de tratamiento fueran transferidos a la cavidad uterina de la paciente. También estaba prohibido desechar o eliminar embriones, o preservarlos para su transferencia a ciclos subsecuentes de la misma u otras pacientes. Se prohibió cualquier manipulación del código genético del embrión, así como toda forma de experimentación sobre el mismo. La prohibición se extendió a cualquier comercio con células germinales —óvulos y

\footnotetext{
1 García Ramírez (coord.), La jurisprudencia de la Corte Interamericana de Derechos Humanos, México, UNAM, Instituto de Investigaciones Jurídicas, 2008, pp. LXIV y LXV.
} 
espermatozoides - para ser destinados a tratamiento de pacientes de técnicas de reproducción asistida.

Dos meses después, el 7 de abril, se presentó un recurso de inconstitucionalidad contra el decreto bajo el argumento de que la fecundación in vitro y la transferencia de embriones regulada en el mismo violaban el derecho a la vida y la dignidad del ser humano.

Mientras el recurso se resolvía, la fecundación in vitro fue practicada en Costa Rica entre 1995 y 2000. En ese lapso nacieron 15 niños, hasta que la técnica fue declarada inconstitucional por la Sala Constitucional de Costa Rica mediante sentencia 2000-02306 del 15 de marzo de 2000. En esta sentencia, la Sala determinó que las prácticas de fecundación in vitro atentaban contra la vida y la dignidad del ser humano. En palabras de la Sala Constitucional: ${ }^{2}$

El embrión humano es persona desde el momento de la concepción, por lo que no puede ser tratado como objeto, para fines de investigación, ser sometido a procesos de selección, conservado para su congelación, y lo que es fundamental para la Sala, no es legítimo constitucionalmente que sea expuesto a un riesgo desproporcionado de muerte...

La objeción principal de la sala es que la aplicación de la técnica importa una elevada pérdida de embriones, que no puede justificarse en el hecho de que el objetivo de ésta es lograr un ser humano, dotar de un hijo a una pareja que de otra forma no podría tenerlo. Lo esencial es que los embriones cuya vida se procura primero y luego se frustra son seres humanos y el ordenamiento constitucional no admite ninguna distinción entre ellos...

Según la Sala... las condiciones en las que se aplica actualmente (la fertilización in vitro), llevan a concluir que cualquier eliminación o destrucción de concebidos — voluntaria o derivadas de la impericia de quien ejecuta la técnica o de la inexactitud de ésta - viola el derecho a al vida, por lo que la técnica no es acorde con el Derecho de la Constitución y por ello el reglamento cuestionado es inconstitucional por infracción al artículo 21 de la Constitución Política y 4 de la Convención Americana sobre Derechos Humanos.

2 Sentencia núm. 2000-02306 del 15 de marzo de 2000, emitida por la Sala Constitucional de Costa Rica, Expediente núm. 95-001734-007-CO. 
En aquel momento varias parejas estaban en lista de espera para que se les practicara una fecundación in vitro, la cual no pudo realizarse después de la sentencia.

El 19 de enero de 2001, el peticionario - las parejas que estaban en lista de espera - sostuvo que la sentencia enunciada contravenía diversos derechos de las personas citados en el mismo escrito, los cuales están reconocidos por la Convención Americana Sobre Derechos Humanos. Por su parte, el Estado sostuvo que los hechos del caso no caracterizaban violación a los derechos humanos garantizados por esa Convención.

\section{DERECHOS ANALIZADOS EN EL INFORME}

Para fines de análisis del Informe, me permití agrupar las posiciones del peticionario y del Estado, además de la conclusión de la Comisión por temas. Posteriormente la misma Comisión realizó una lectura conjunta para integrar los diferentes derechos revisados.

1) Infertilidad y derecho a la salud

2) Derecho a la vida privada

3) Derecho a fundar una familia

4) Lectura conjunta

\section{Infertilidad y derecho a la salud}

a) El peticionario sostuvo que las presuntas víctimas eran pacientes diagnosticados con infertilidad severa. Según esta posición, la incapacidad de procrear causa enormes sufrimientos a quienes la padecen; el no poder tener herederos provoca en la pareja un agudo sentimiento de inferioridad que afecta su salud. A consecuencia de la decisión de la Sala Constitucional, las presuntas víctimas no pudieron someterse a dicho tratamiento en su país, o tuvieron que practicárselo en el extranjero.

b) El Estado indicó que la fecundación in vitro no es una cura contra las causas de infertilidad, sino que representa un complejo recurso 
técnico que intenta superar artificialmente dicha condición. La prohibición no condenó por sí misma a las parejas en lista de espera a no tener descendencia, pues el origen de la incapacidad para concebir no depende de una resolución judicial, sino de cuestiones biológicas. También señaló que la Sala Constitucional determinó que el derecho relativo a procrear debe ser subordinado al derecho absoluto a la vida, ya que sería contradictorio aceptar una vida a costa de la pérdida de otras, hecho que sucede con la técnica de fecundación in vitro.

c) La Comisión se refirió a la consideración de la Organización Mundial de la Salud que se refiere a la infertilidad como "una enfermedad del sistema reproductivo definida por la imposibilidad de alcanzar un embarazo clínico luego de haber mantenido relaciones sexuales sin protección durante doce meses o más" (traducción no oficial). ${ }^{3}$ Numerosas causas de infertilidad se deben a problemas físicos concretos que requieren tratamiento médico. Asimismo, en muchos casos, la imposibilidad de lograr un embarazo puede generar trastornos psicológicos o sufrimiento psíquico. Cabe recordar que la Organización Mundial de la Salud ha definido a la salud como un "estado de completo bienestar físico, mental y social; y no solo la ausencia de enfermedades o dolencias". El Protocolo de San Salvador, atendiendo a la Organización Mundial de la Salud, consagra que toda persona tiene derecho a la salud, entendida ésta como el disfrute del más alto nivel de bienestar físico, mental y social. ${ }^{4}$ La Comisión afirmó que las parejas infértiles que perciben un sufrimiento real, físico y psicológico por no poder procrear biológicamente no disfrutan plenamente de su derecho a la salud; agregó, además, que la utilización de la fecundación in vitro para combatir la infertilidad también está estrechamente vinculada con el goce de los beneficios del progreso científico, derecho que ha sido reconocido internacionalmente en el Pacto Internacional de Derechos Económicos, Sociales y Culturales. ${ }^{5}$

The International Committee for Monitoring Assisted Reproductive Technology (ICMART) and The World Health Organization (WHO) Revised, Glossary on ART Terminology, 2009, publicado por Human Reproduction, vol. 24, núm. 11, pp. 2683-2687, citada por el mismo Informe de la CIDH.

4 Artículo 10 del protocolo de San Salvador

5 El artículo 15 b) del Pacto Internacional de Derechos Económicos, Sociales y Culturales dispone que "Los Estados Partes en el presente Pacto reconocen el derecho de toda persona a 


\section{Derecho a la vida privada}

a) El peticionario alegó que el Estado no puede interferir en la decisión de la pareja de tener hijos, pues de hacerlo estaría invadiendo la privacidad e interfiriendo en la vida sexual y reproductiva de las personas. Tal acción configuraría una violación del artículo 11 de la Convención Americana. ${ }^{6}$ La relación entre médico y paciente es absolutamente privada, por lo que el Estado carece de facultades para prohibir a una persona someterse o no a dicho tratamiento. No hubo posición del Estado en este punto.

b) El análisis de la CIDH parte de la interpretación del artículo 11 de la Convención Interamericana sobre Derechos Humanos. De acuerdo con este precepto, en su inciso (1): "toda persona tiene derecho al respeto de su honra y al reconocimiento de su dignidad”. Por su parte, el punto 2 expresa: "nadie puede ser objeto de injerencias arbitrarias o abusivas en su vida privada, en la de su familia y de la correspondencia, ni de ataques ilegales a su honra o reputación”. Asimismo, el artículo 11(3) dispone que tal derecho debe ser protegido por la ley.

La CIDH invocó jurisprudencia de la Corte Europea de Derechos Humanos, la cual ha sostenido que la protección a la vida privada incluye el respeto tanto a la decisión individual de convertirse en padre o madre, ${ }^{7}$ así como a la decisión de la pareja de convertirse en padres genéticos, ${ }^{8} \mathrm{y}$ esta elección corresponde a una faceta particularmente importante de la existencia individual y de la identidad de una persona.

En aplicación de los anteriores estándares al presente caso, la $\mathrm{CIDH}$ consideró que la decisión de las parejas — presuntas víctimas — de te-

gozar de los beneficios del progreso científico y de sus aplicaciones”.

6 El peticionario no mencionó el texto del artículo 11 de la Convención Americana pero éste expresa en sus párrafos 2 : "Nadie puede ser objeto de injerencias arbitrarias o abusivas en su vida privada, en la de su familia, en su domicilio o en su correspondencia, ni de ataques ilegales a su honra o reputación” y el 3. "Toda persona tiene derecho a la protección de la ley contra esas injerencias o esos ataques".

7 Corte Europea de Derechos Humanos, Pretty v. The United Kingdom, Aplicación 2346/02, 29 de abril 2002, párrafo 61. Citada en el Informe de la CIDH.

8 Corte Europea de Derechos Humanos, Dickson $v$ The United Kindom , Aplicación 4436/04, 4 de diciembre de 2007. Citada en el informe de la CIDH. 
ner hijos biológicos pertenece a la esfera más íntima de su vida privada y familiar. Asimismo, la forma cómo se construye dicha decisión es parte de la autonomía y de la identidad de una persona tanto en su dimensión individual como de pareja, y en consecuencia se encuentra protegida por el artículo 11 de la Convención Americana.

\section{Derecho a fundar una familia}

a) El peticionario argumentó que el reconocimiento del derecho a procrear es un presupuesto imprescindible para el ejercicio del derecho a fundar una familia, y la incapacidad de procrear causa enormes sufrimientos a quienes la padecen, tales como sentimientos de inferioridad y culpabilidad.

b) Por su parte, el Estado se refirió al criterio sustentado por la Sala Constitucional de considerar una contradicción el aceptar la posibilidad de crear una vida a costa de la pérdida de otras vidas humanas, lo cual sucede con la técnica de fecundación in vitro.

c) La Comisión consideró que el derecho a fundar una familia se encuentra reconocido en el artículo 17(2) de la Convención Americana - "se reconoce el derecho del hombre y la mujer a contraer matrimonio y a fundar una familia..”- , así como en la Declaración Universal de Derechos Humanos ${ }^{9}$ y en el Pacto Internacional de Derechos Civiles y Políticos. Sin embargo, la CIDH, en concordancia con la Corte Europea de Derechos Humanos, ha señalado anteriormente que el derecho a fundar una familia está sujeto a ciertas condiciones del derecho nacional, aunque las limitaciones que por esa vía se introducen no deben ser tan restrictivas que se dificulte la propia esencia del derecho. ${ }^{10}$

9 En su artículo 16, inciso 1, establece el derecho de los hombre y las mujeres a casarse y fundar una familia lo mismo que el artículo 23.2 del Pacto Internacional de derechos Civiles y Políticos.

10 CIDH María Elena Morales de Sierra y Guatemala, Informe núm. 4/01, Caso 11,625, 19 de enro de 2001, párr. 40: Corte Europea de D.H. Rees v. Reino Unido, serie A, núm. 106 17 de octubre de 1986 párr. 50. Citada en el mismo Informe de la CIDH. 
De acuerdo con las consideraciones planteadas, la Comisión sostuvo que de una lectura conjunta de los artículos 11 y 17 de la Convención Americana se desprende que la protección del derecho a conformar una familia comprende la decisión de convertirse en padre o madre biológico, e incorpora la opción y el acceso a los medios pertinentes para materializarla. Esta decisión es parte de la esfera más íntima de la vida y corresponde al ejercicio exclusivo de la autonomía de cada persona y/o pareja.

Sin embargo, la Comisión reconoció que tanto el derecho a la vida privada y familiar como el derecho a fundar una familia pueden ser objeto de ciertas limitaciones; por ello, resolvió evaluar, con base en ciertos criterios, si las restricciones en el ejercicio de los derechos contemplados en los artículos 11 y 17 de la Convención Americana sobre Derechos Humanos son compatibles con dicho instrumento o si, por el contrario, se trató de limitaciones arbitrarias y por lo tanto violatorias del mismo.

\section{TEST DE LA COMISIÓN}

Para determinar si el fin de proteger la vida del embrión, perseguido por el Estado, guardaba relación con las dimensiones de las prohibición a la fecundación in vitro, la Comisión llevó a cabo un test que definiera la injerencia en el ejercicio de los derechos consagrados en los artículos 11 y 17 de la Convención; la compatibilidad de dicha ingerencia con la Convención Americana; la idoneidad y la existencia de alternativas menos restrictivas.

\section{Posición del peticionario}

El peticionario indicó que la interpretación de la Sala Constitucional sobre el destino final del embrión humano y su consideración como persona humana con derecho a la vida de carácter absoluto "evidencia 
una percepción subjetiva que confiere culpabilidad a los profesionales que practican la fecundación in vitro por un hecho que ocurre en la naturaleza, atribuible a la selección natural de las especies”. ${ }^{11}$ En este sentido, el peticionario se pregunta ¿por qué, cuando la pérdida gestacional temprana es consecuencia de la acción del hombre, es cuestionada y prohibida por la Sentencia de la Sala?

\section{Posición del Estado}

Por su parte, el Estado invocó los argumento sustentados en la sentencia de la Sala Constitucional — ya referidos en este estudio- y citó el artículo 4.1 de la Convención Americana que establece expresamente la posibilidad de protección a la vida desde el momento de la concepción, independientemente de la interpretación que se le dé a la calificación "en general". Lo relevante es que el artículo establece la protección de la vida desde el momento de la concepción, y que el Estado de Costa Rica ha escogido esa última posibilidad: cualquier eliminación o destrucción de embriones, voluntaria o derivada de la impericia de quien ejecuta la técnica o de la inexactitud de ésta, viola el derecho a la vida.

\section{Análisis de la Comisión}

La Comisión se tomó el cuidado de establecer los criterios para evaluar si las restricciones en el ejercicio de los derechos contemplados en los artículos 11 y 17 de la Convención Americana son compatibles con dicho instrumento o si, por el contrario, la prohibición de acceder a la fecundación in vitro se convirtió en una limitación arbitraria y por lo tanto violatoria del mismo.

El artículo 30 de la misma Convención establece que las restricciones al goce y ejercicio de los derechos y libertades sólo pueden ser aplicadas conforme a leyes que se dicten por razones de interés general y con el propósito para el cual han sido establecidas.

11 Punto 20 del Informe de la Comisión Interamericana de Derechos Humanos núm. $85 / 10$ caso 12.361 . 
Para evaluar el alcance de esas restricciones, tanto la Comisión como la Corte Interamericana han recurrido al uso de criterios que permitan evaluar en un caso concreto la legitimidad de la restricción de un derecho o la interferencia estatal en el ejercicio del mismo. Los criterios que se han aplicado son los de: legalidad, fin legítimo, idoneidad, existencia de alternativas menos restrictivas, y proporcionalidad.

\section{A. Legalidad}

La Comisión concluyó que la Sala Constitucional de Costa Rica era la instancia a quien le correspondía emitir la decisión de prohibir la fecundación in vitro conforme la legislación interna de Costa Rica. En consecuencia, el requisito de estar previsto por ley se cumplió.

\section{B. Fin legítimo}

El argumento principal del Estado subyace en la protección de la vida de los embriones no implantados, establecida en el artículo 21 de la Constitución Política de Costa Rica, el cual dispone que "la vida humana es inviolable”. En ese sentido, el Estado tenía un fin legítimo en términos generales, sin embargo, las medidas que los Estados adopten en ejercicio de dicho fin no pueden restringir o interferir arbitrariamente en los derechos contemplados en la Convención Americana sobre Derechos Humanos.

\section{Idoneidad}

Dado el interés legítimo del Estado por proteger el derecho a la vida, existe una relación causal entre dicho interés y la imposición de controles sobre la práctica de la fecundación in vitro. Por lo tanto, la Comisión considera que la misma cumple con el requisito de idoneidad.

D. Existencia de alternativas menos restrictivas

El requisito de necesidad incorpora la determinación de si el Estado contaba o no con otros medios menos restrictivos e igualmente idóneos para contribuir a lograr el fin legítimo que persigue. 
En América no hay un tratamiento uniforme respecto al control y utilización de la FIV; sin embargo, la información disponible indica que a raíz de la sentencia de la Sala Constitucional, Costa Rica se convirtió en el único país en el hemisferio americano en el que se prohíbe la fecundación in vitro, aun cuando muchos de los países de la región protegen la vida antes del nacimiento en sus leyes o Constituciones, como sucede en Argentina, Chile, Colombia, Guatemala, Ecuador, Panamá, Perú o Uruguay.

Para las víctimas — cuya infertilidad hacía inviable otro método de reproducción asistida - la prohibición legal de practicar la fecundación in vitro significó una supresión de la identidad personal y de la autonomía para decidir tener hijos biológicos, para controlar su propia capacidad reproductiva y, en suma, para desarrollar su proyecto de vida.

La Comisión concluyó que existían formas menos restrictivas para satisfacer el objetivo buscado por el Estado y acomodar los intereses en juego. La Sala Constitucional no consideró otras alternativas para proteger la vida y respetar al mismo tiempo los derechos de las parejas infértiles, por lo que la prohibición absoluta de la práctica no cumple con el requisito de necesidad para lograr el fin perseguido. Por tanto, dicha prohibición constituyó una interferencia arbitraria y una restricción incompatible con la Convención Americana en el ejercicio de los derechos a la vida privada, familiar y de fundar una familia, consagrados en los artículos 11 y 17 de la Convención Americana en relación con el artículo 1.1 del mismo instrumento. ${ }^{12}$

\section{DERECHO A LA IGUALDAD ANTE LA LEY E IGUAL PROTECCIÓN DE LA LEY, ARTíCULO 24 DE LA CONVENCIÓN AMERICANA SOBRE DERECHOS HUMANOS}

En forma independiente al análisis de los otros derechos, la Comisión se refirió a la igualdad ante la ley e igual protección de la ley. La Conven-

12 "Los Estados Partes en esta Convención se comprometen a respetar los derechos y libertades reconocidos en ella y a garantizar su libre y pleno ejercicio a toda persona que esté sujeta a su jurisdicción, sin discriminación alguna por motivos de raza,color, sexo, idioma, religión, opiniones políticas o de cualquier otra índole, origen nacional o social, posición económica, nacimiento o cualquier otra condición social”. 
ción Americana sobre Derechos Humanos y la Corte Interamericana han señalado reiteradamente que el derecho a la igualdad y a la no discriminación constituye el eje central del sistema interamericano de derechos humanos. Asimismo, se ha establecido que "acarrea obligaciones erga homnes" de protección que vinculan a todos los Estados y generan efectos con respecto a terceros, incluso particulares. ${ }^{13}$

La CIDH ha establecido que el examen de normas y políticas sobre la base del principio de igualdad efectiva y no discriminación abarca también el posible impacto discriminatorio de estas medidas, aun cuando parezcan neutrales en su formación o se trate de medidas de alcance general no diferenciado. ${ }^{14}$ Por su parte, el Comité de Derechos Económicos, Sociales y Culturales ha definido a la discriminación indirecta como "leyes, políticas o prácticas en apariencias neutras pero que influyen de manera desproporcionada en los derechos del Pacto (Pacto Internacional de Derechos Económicos, Sociales y Culturales) afectados por los motivos prohibidos de discriminación". ${ }^{15}$ De igual manera, la Corte Europea de Derechos Humanos ha desarrollado el concepto de discriminación indirecta estableciendo que cuando una política o medida general tiene un efecto desproporcionadamente perjudicial en un grupo particular no se excluye que sea considerada discriminatoria, aun si no fue dirigida específicamente a ese grupo. ${ }^{16}$

Cabe aclarar que la Comisión no se refirió al Decreto que reguló la fertilización asistida en Costa Rica, sino únicamente a la prohibición de acceder a un procedimiento que hubiera podido contribuir a que

13 Corte Interamericana de Derechos Humanos. Condición Jurídica y Derechos de los Migrantes Indocumentados. Opinión Consultiva OC 18/03 del 17 de septiembre de 2003, Serie A, núm. 18, párr. 173(5) Citado en el informe de la CIDH.

${ }_{14} \mathrm{CIDH}$, Acceso a la Justicia para las Mujeres Victimas de Violencia en las Américas, OEA/ Serie LV/II. Doc.68, 20 de enero de 2007, párr. 90. Asimismo véase Corte IDH. Caso de las Niñas Yean y Bossico, sentencia del 8 de septiembre de 2005, Serie C, núm. 130, párr. 141. Citado en el Informe de la CIDH.

15 Naciones Unidas, Comité de Derechos Económicos, Sociales y Culturales, Observación General núm. 20, La no discriminación y los derechos económicos, sociales y culturales (artículo 2 párrafo 2 del Pacto Internacional de Derechos Económicos, Sociales y Culturales) 2 de julio de 2009.

16 Corte Europea de Derechos Humanos, Hoogendijk v. Holanda, Aplicación núm. 5864/100, 2005. Citado en el Informe de la CIDH. 
las víctimas del caso tuvieran hijos biológicos, medida contenida en la decisión de la Sala Constitucional.

La Comisión consideró que la prohibición de acceder a un procedimiento de fecundación in vitro tuvo dos efectos que se encuentran bajo el alcance del derecho a la igualdad: i) impidió a las víctimas superar la situación de desventaja en la que se encontraban a través del beneficio del progreso científico, en particular, de un tratamiento médico, y ii) tuvo un impacto específico y desproporcionado frente a las mujeres.

Si bien la situación de infertilidad de las víctimas no es en forma alguna atribuible al Estado de Costa Rica, la técnica de reproducción asistida mediante fecundación in vitro constituía el único tratamiento médico que les hubiera abierto la posibilidad de procrear biológicamente. Aunque la situación de desventaja no fue creada por el Estado, la permanencia de la misma —a pesar de que existían medios para superarla o, al menos, disminuirla - sí es atribuible al Estado.

La prohibición completa de un medio que permitiría alcanzar una situación de igualdad exacerba las diferencias de las víctimas del caso frente a las personas y/o parejas fértiles e, incluso, frente a las parejas y/o personas infértiles que contaban con otros medios para procrear biológicamente. Ello equivale a perpetuar una distinción que sólo deberá considerarse compatible con la Convención Americana si es razonable y objetiva. Los criterios de idoneidad y fin legítimo ya fueron analizados por la Comisión en la sección de los derechos a la vida privada y familiar, y concluyó que existían alternativas menos restrictivas que la prohibición de la fecundación asistida.

Por otra parte, si bien la infertilidad puede afectar a hombres y mujeres, la utilización de las tecnologías de reproducción asistida recae especialmente en el cuerpo de las mujeres y, por lo tanto, su prohibición incide directamente en la autonomía de las mujeres respecto a su cuerpo. Con base a lo anterior, la Comisión resolvió que el Estado de Costa Rica violó el derecho a la igualdad y el principio de no discriminación consagrados en el artículo 24, el cual garantiza la equidad y protección igual de la ley, ${ }^{17}$ y en el artículo 1.1 de la Convención Americana, en

17 Textualmente el artículo 24 expresa: "Todas las personas son iguales ante la ley. En consecuencia, tienen derecho, sin discriminación, a igual protección de la ley”. 
relación con la obligaciones establecidas en el artículo 2o. del mismo instrumento, ${ }^{18}$ en perjuicio de los quejosos.

\section{RECOMENDACIONES DE LA COMISIÓN INTERAMERICANA De Derechos Humanos}

En virtud de las consideraciones presentadas en el Informe, tras valorar las posiciones de las partes y analizar los hechos del caso, la CIDH concluyó que el Estado de Costa Rica es responsable por la violación de los derechos consagrados en los artículos 11.2, 17.2 y 24 de la Convención Americana, en relación con las obligaciones establecidas en los artículos 1.1 y 2 de dicho instrumento, en perjuicio de quienes presentaron la petición y emitió sus

1) Levantar la prohibición de la fecundación in vitro en el país a través de los procedimientos legales correspondientes.

2) Asegurar que la regulación que se otorgue a la práctica de la fecundación in vitro a partir del levantamiento de la prohibición sea compatible con las obligaciones estatales respecto a los derechos consagrados en los artículos 11.2, 17.2 y 24, según lo establecido a lo largo del presente informe. En particular, que las personas y/o parejas que lo requieran y así lo deseen puedan acceder a las técnicas de fecundación in vitro de forma que dicho tratamiento contribuya efectivamente a su finalidad.

3) Reparar íntegramente a las víctimas del presente caso tanto en el aspecto material como moral, incluyendo medidas de satisfacción por los daños ocasionados.

18 El artículo 2 de la Convención Americana sobre Derechos Humanos expresa: . "Si el ejercicio de los derechos y libertades mencionados en el artículo 1 no estuviere ya garantizado por disposiciones legislativas o de otro carácter, los Estados partes se comprometen a adoptar, con arreglo a sus procedimientos constitucionales y a las disposiciones de esta Convención, las medidas legislativas o de otro carácter que fueran necesarias para hacer efectivos tales derechos y libertades". 
La Recomendación fue firmada el 14 de julio de 2010, pero hubo una disidencia en relación con el artículo 24 de la Convención Americana sobre Derechos Humanos. Tres miembros de la Comisión determinaron que no hay discriminación en la Sentencia de la Sala Constitucional en virtud de que la misma prohíbe el acceso a los procedimientos in vitro por igual a todos los individuos y parejas del país.

\section{SigNifiCAdo DE LA RESOLUCIÓN EN EL CONTINENTE AMERICANO}

El Informe de la Comisión Interamericana de Derechos Humanos y sus Recomendaciones al Estado de Costa Rica representan un parte aguas en el continente americano. Esta aseveración se funda en la importancia del análisis que la Comisión formula sobre ciertos temas que han desatado polémica entre la mayoría de los países que han intentado - $\mathrm{O}$ que ya han modificado_ sus legislaciones en torno a la fertilización asistida.

Las técnicas de esta procreación no natural plantean complejas interrogantes éticas y jurídicas, e incluso algunas controversias. De manera esquemática podemos distinguir dos polos que reflejan el conflicto: por un lado, la primacía de libre acceso a las técnicas y, por el otro, la primacía de la protección de la vida de los embriones que se generan durante los procesos reproductivos artificiales.

El llamado embrión —al que técnicamente deberíamos referirnos como cigoto o blastocisto, ya que en esa etapa de desarrollo carece de tejido embrionario - está en el centro del debate. El distinguido médico y filósofo francés Claude Sureau ${ }^{19}$ se refiere al embrión como ese "ser prenatal, misterioso y fantasmagórico que sólo se nos revela a través de los medios modernos de investigación, tales como la ecografía y la asistencia médica para la procreación”. En su opinión, la dualidad de las actitudes frente a ese ser son profundamente ambiguas y hasta podrían catalogarse de "esquizofrénicas" por las oposiciones conceptuales tan radicales que se manifiestan en su entorno. En el mismo sentido, Juliana

19 Claude Sureau, “L'Être Prénatal. Illusion Biologique, Réalité Humaine o Enjeu Politique”, Science, Étique et Droit. Bajo de la dirección de Nicole M. Le Dourian Catherine Puigelier. Odile Jacob, Francia pp. 202-217. 
González ${ }^{20}$ sostiene que las posiciones encontradas cancelan la posibilidad de avance a toda discusión. Esto ocasiona que se realicen prácticas fuera de la discusión abierta y racional, al margen de la valoración y del control moral, con el incremento de los riesgos implicados.

Es en medio de esta discusión donde se sitúa el caso presentado por el peticionario contra la sentencia de la Sala Constitucional, la cual prohibió la fecundación in vitro en el año 2000, que en un afán por proteger la vida de los embriones. En su informe, los miembros de la Comisión tuvieron la fina perspicacia para comprender que no debían entrar al inacabable debate sobre la protección del embrión, sino que era mejor analizar si la prohibición a ese tipo de fertilización constituyó una interferencia idónea, proporcional y justificada por el fin perseguido, o si la sentencia fue excesiva, frente a la existencia de alternativas menos restrictivas. Esos mismos integrantes de la CIDH consideraron que la interdicción afectó el derecho a la salud de las personas aquejadas de problemas de fertilidad, a la libertad de tomar decisiones sobre un ámbito particularmente importante de la vida privada y familiar, y representó una limitación a fundar una familia conforme a las decisiones de la pareja; además, violó el derecho a la igualdad y al principio de no discriminación a que tiene derecho toda persona, en lo individual o en pareja.

Resulta un tema ya común mencionar la ambigüedad que existe en el continente americano respecto al enfoque que han tomado las técnicas de reproducción asistida. En especial, los países latinoamericanos carecen de leyes sistemáticas sobre esta materia. En la mayoría de los casos sólo existen algunos principios generales aplicables a tales técnicas que figuran en los códigos civiles, penales o en leyes sanitarias, ${ }^{21}$ y son varios los Estados en los cuales los procesos para legislar sobre reproducción asistida han sido extremadamente lentos o, incluso, en los cuales ha existido la intención premeditada de detenerlos.

20 González, Juliana, “Embrión humano y dignidad humana”, Células troncales, aspectos científicos, filosóficos y jurídicos, México, UNAM, Instituto de Investigaciones Jurídicas, 2005, p. 61

21 Andorno, Roberto, “Técnicas de reproducción asistida”, en Brena, Ingrid y Teboul, Gérard (coords.), Hacia un instrumento regional interamericano sobre bioética, experiencias y expectativas, México, UNAM, Instituto de Investigaciones Jurídicas, 2009, pp. 195-212. 
En Argentina se han elaborado mas de 20 proyectos de ley. En México, cada partido político ha presentado iniciativas ante el Senado de la República — un total de siete- de las cuales dos fueron presentadas por el Partido Revolucionario Institucional; además, existen otras iniciativas presentadas ante la Cámara de Diputados. Al momento de comentar esta resolución, las discusiones se encuentras atoradas gracias a las distintas ideologías de los partidos y a la cerrazón imperante.

Ante este impasse, una buena estrategia implicaría contar con una sociedad informada que hiciera oír su voz ante los distintos órganos gubernamentales, en especial el legislativo. Es necesario que las personas reciban información sobre los avances de las técnicas reproductivas y de sus posibilidades reales; que conozcan su derecho a la salud reproductiva y al acceso a los adelantos científicos y tecnológicos; su derecho a la privacidad, a fundar una familia, a ser tratados en igual forma y a no ser discriminados.

No existe en los textos legales un derecho expreso a la reproducción; los seres humanos nos hemos reproducido sin necesidad de que el derecho nos autorice. Estos textos tampoco otorgan un poder o facultad para exigir a alguien su reproducción y sin embargo guardan una evidente conexión con la libertad y la dignidad de las personas. Ello significa que cada individuo tienen la facultad para tener o no hijos, para decidir sobre su número y el espaciamiento entre ellos.

Cuando las personas son sanas en términos de fertilidad y viven en parejas heterosexuales, esa libertad procreacional es muy amplia y, podría decirse, casi absoluta. Los cuestionamientos éticos y jurídicos se inician cuando las personas, por problemas de fertilidad, se ven precisadas a acudir a la práctica médica. En tales casos, el derecho a la reproducción artificial ya no es ilimitado, y sus limitaciones derivan del reconocimiento de otros derechos - tanto de los mismos involucrados como de terceros - y a ciertos principios como la indicación médica y la proporcionalidad de los medios que se empleen.

Corresponde a los especialistas determinar la complejidad de cada caso: si se requieren tratamientos farmacológicos y hormonales o si, en cambio, es preciso acudir a cualquiera de las distintas técnicas de reproducción asistida. Si el problema puede resolverse por una inseminación artificial no debe intentarse la fecundación in vitro, y la indicación de un 
donante ajeno sólo se justifica cuando los gametos de algún miembro de la pareja no sean aptos para lograr una fecundación. ${ }^{22}$

También deben existir limitaciones al derecho a la procreación artificial cuando, al amparo del mismo, se pretendan realizar técnicas en forma caprichosa que tenga como finalidad la selección de sexo sin justificante médico o la selección de ciertos atributos físicos considerados como deseables: color de la piel, de ojos, de pelo, o en aquellos casos donde exista un riesgo de transmisión de ciertas enfermedades, como el síndrome de inmunodeficiencia adquirida. Cada acción debe juzgarse a la luz del problema específico de salud y ser sometido a controles y limitaciones por parte de los poderes públicos debido a la complejidad y riesgos asociados a las técnicas de reproducción asistida. Sin embargo, es muy distinto establecer limitantes cuando éstas se encuentran justificadas y no son excesivas, a establecer una tajante prohibición o a no legislar, tomando en cuenta todos los derechos involucrados en la fertilización artificial.

Ésta fue precisamente la conclusión a la que llegó la Comisión. Está claro que a sus integrantes les correspondió únicamente analizar un caso concreto: la petición formulada por un grupo de parejas a las que se les impidió someterse a una fecundación in vitro como resultado de una sentencia de la Sala Constitucional de Costa Rica. Sin embargo, la resolución será un punto de partida para posteriores reflexiones jurídicas, las cuales deberán girar en torno a definir hasta qué punto le corresponde a los Estados limitar derechos reconocidos tanto por la Convención Americana sobre Derechos Humanos como por sus propios derechos internos, cuándo estas limitaciones estén justificadas en la protección del llamado embrión y lo consideren persona, una connotación con una carga ideológica y religiosa que, aunque respetable, no es compartida por el total de la población.

Las alternativas que ofrecen los avances científicos y tecnológicos no deben ser desdeñadas cuando ofrecen a las personas con problemas de fertilidad la posibilidad de hacer efectivos sus derechos reproductivos. Un Estado de derecho, en donde la democracia y los principios que de

22 Abellán, Fenando, Voz "Derechos reproductivos", Enciclopedia de Derecho y Bioética, t. II, Granada, Easy Read Book Holder Company, 20011, pp. 570 y ss. 
ella emanan imperen, debe aceptar, permitir, delimitar y controlar las nuevas técnicas de reproducción asistida.

El Informe y las Recomendaciones elaborados por la Comisión Interamericana de Derechos Humanos por sí solas ya irradiarán a todos los Estados del continente americano. Ahora, tomará tiempo antes de observar la forma en que el Estado de Costa Rica, sede de la Corte Interamericana de Derechos Humanos, enfrentará una sentencia que pudiera asumir los argumentos elaborados por la Comisión Interamericana.

\section{BIBLIOGRAFÍA}

Claude Surreau, L'Étre Prénatal. Illusion Biologique, Réalité Humaine o Enjeu Politique, Science, Étique et Droit, bajo de la dirección de Nicole M. Le Dourian Catherine Puigelierb Odile Jacob, Francia.

GARCÍA RAmíREZ, Sergio (coord.), La Jurisprudencia de la Corte Interamericana de Derechos Humanos, México, UNAM, Instituto de Investigaciones Jurídicas, 2008.

GONZÁlEZ, Juliana, "Embrión humano y dignidad humana”, Células troncales, aspectos científicos, filosóficos y jurídicos, México, UNAM, Instituto de Investigaciones Jurídicas, 2005.

ANDORNO, Roberto, "Técnicas de reproducción asistida”, en BRENA, Ingrid y TeBOUL, Gérard (coords.), Hacia un instrumento regional interamericano sobre bioética, experiencias y expectativas, México, UNAM, Instituto de Investigaciones Jurídicas, 2009.

Abellán, Fenando, Voz "Derechos reproductivos", Enciclopedia de Derecho y Bioética, t. II, Granada , Easy-read Book Holder Company, 2011. Informe de la Comisión Interamericana de Derechos Humanos Num.85/10 CASO 12.361 Fondo Gretel Artavia Murillo y otros (Fecundación InVitro) Costa Rica 14 de julio de 2010. 